\title{
Spinning System for Pineapple Leaf Fiber via Cotton Spinning System by Solo and Binary Blending and Identifying Yarn Properties
}

\author{
Khusniddin Ismoilov, Sachin Chauhan, Mingxing Yang, Quan Heng \\ Chemistry and Chemical Engineering, Wuhan Textile University, Wuhan, China \\ Email: husmaf9396husmaf9396@gmail.com, sachinch20.94@gmail.com, husmaf9396husmaf9396@gmail.com
}

How to cite this paper: Ismoilov, K., Chauhan, S., Yang, M. and Heng, Q. (2019) Spinning System for Pineapple Leaf Fiber via Cotton Spinning System by Solo and Binary Blending and Identifying Yarn Properties. Journal of Textile Science and Technology, 5, 86-91.

https://doi.org/10.4236/jtst.2019.54008

Received: July 11, 2019

Accepted: September 22, 2019

Published: September 25, 2019

Copyright $\odot 2019$ by author(s) and Scientific Research Publishing Inc. This work is licensed under the Creative Commons Attribution International License (CC BY 4.0).

http://creativecommons.org/licenses/by/4.0/

\begin{abstract}
By nature, pineapple fiber (PALF) obtained from pineapple leaf is a smooth, shiny and white natural cellulosic fiber. In current investigation of spinning technique for pineapple leaf fiber based on cotton spinning method comparison of produced yarn properties has been reported. For one of the investigations of this study, the fibers were cut into staple length and various properties of fibers were analyzed. Data and results acquired from this illustrated that there is excellent spinnability on the fiber. Two separate researches were conducted with consideration to produce resultant yarn by spinning of PALF. Yarn derived by solo spinning technique of $100 \%$ PALF and PALF blending with polyester and cotton fibers through binary blending technique in equal proportion has been spun, then yarn count, tensile properties, yarn evenness, hairiness have been evaluated and analyzed. The results from numerical simulations analysis indicated that yarn obtained from the Pineapple leaf fiber (PALF) had great potential to be used in apparels.
\end{abstract}

\section{Keywords}

Cellulose Fiber, Cotton Spinning Technique, Spinnability, Tensile Strength, Evenness, Hairiness, Pineapple Leaf Fiber

\section{Introduction}

Cellulose fiber has become a trend in the development of textile. Pineapple leaf fiber (PALF) is a natural cellulosic fiber collected from pineapple leaves. Every year tones of PALF are being produced but very small portions are being used [1]. The pineapple leaf is currently being wasted in most regions that grow this plant, with only the fruit itself being utilized. In recent decades, pineapple has become a crop of great importance for the north-east of Brazil, with respect to 
the regional economy [IBGE, 2004]. However, after harvesting, the fruit's leaves (rich in fiber) are placed for pasture for cattle, or in most cases left to rot. This is due to lack of technology suitable for fiber utilization, as well as growers ignorance of the possible uses of fibers, which can generate them extra income. The fibers derived from pineapple leaves are long, with one of the best fineness indexes among vegetal fibers, which make them suitable for many industrial applications [2]. It is estimated by Leao et al. [2010] that production of pineapple fibers per hectare/year yields around 15 tonnes. The fibers can be considered to produce a negative cost, as they are currently dumped for composting. If this material is transformed into something more valuable, this negative cost can be translated into income for growers. Therefore this raw material results in a very low cost of US $\$ 15$ per tonne in the field, compared to softwood fibers at US $\$ 250$ per tonne in the field, representing an excellent opportunity. Pineapple leaf fibers (PALFs) could be a viable solution to the deficiency of long fibers in Brazil, and in many other tropical countries. Brazil is the world's third largest producer of pineapple plant residue, with Thailand and the Philippines as the first and second, respectively. The total planted area in Brazil is about 60,000 hectares, with each hectare resulting in 1.5 tonnes of dry fiber, according to data obtained from Leao et al. [2010] for the Hawaiian variety. Through this raw material it will be possible to identify the crop production chain and bring a new and important resource for growers. Because there are new vegetable fibers being brought to market, there is a need to study in-depth the chemical and morphological characteristics of PALFs and evaluate in detail the optical, surface, and mechanical properties of these fibers. Through these characterizations, it will be possible to make a precise assessment of the market for special papers and composites applications, adding more value to these long fibers. The nano-fibers and nano-whiskers also represent an emerging alternative, thanks to the composition of the pineapple leaf (low lignin content), its high fineness index, and high aspect ratio. [3]. Pineapple leaf fiber are collected from the pineapple leaves either by scrapping, retting, or decortications and used for significant purposes without any additional input cost [4]. PALF is white, creamy and lustrous fiber. Various investigations show that pineapple leaf fiber is mainly composed of cellulose, hemicellulose, lignin, wax, pectin, inorganic and so on, the cellulose content of $56 \%$ - 82\%. PALF contributed with excellent mechanical properties compared to other natural fibers. It has high specific strength and stiffness and it is hydrophilic in nature due to high cellulose content. In addition, these fibers can easily retain dyes. The crystallinity and preferred orientation of crystallites in pineapple fibers are high and the average fracture strength of the pineapple leaf fiber is high and the linear density is low, so there is a high fiber spin ability and yarn quality. Until now, there is no special spinning system have been designated for PALF spinning system [5]. Nowadays PALF are spun into yarns using existing fibers spinning system including jute spinning system, semi-worsted and flax system by binary or multi blending [6]. However, the PALF yarns produced still coarse and still not in line with cotton yarns properties [7]. In this investigation, 
accordance with its effective length and then yarn is made from the fiber, although the various table text styles are provided, the fiber was prepared to spin into cotton spinning system by cutting extracted and pretreated fiber.

\section{Experimental}

\subsection{Materials}

Fiber obtained from Pineapple leaf fiber was purched from RAVI EXPORTS Company Co., Ltd. Cotton fiber with excellent quality and Polyester synthetic fiber were supplied by the Head labaratory of Collage of Chemistry and Chemical engineering at Wuhan Textile University. The instruments and apparatuses were provded by the Labaratory of Collage.

\subsection{Preparation and Characterization of PALF Fibers}

PALF fibers obtained and prepared were cut into staple length and different properties of fiber i.e. fiber length, fiber morphology, tensile properties were analyzed. Then fibers were blended with cotton in equal proportion (50\% PALF $+50 \%$ cotton) followed by blended with polyester in equal proportion (50\% PALF $+50 \%$ polyester). Then yarns were produced from both aforementioned blended fibers. Another yarn also produced from 100\% PALF fiber. Laboratory scale opening, carding, drawing, simplex and ring frame were used to manufacture all the yarns. The characteristics of all the yarns i.e. yarn count, evenness, hairiness were studied by using testing equipment in Wuhan Textile University and a comparison among them are made. The cross sectional and longitudinal views of pineapple fibers (PALF) were analyzed by Scanning electron microscope (SEM) and the images were recorded.

\section{Result and Discussion}

\subsection{Morphological Structures of Fiber}

Scanning electron microscope (SEM) image of the surface of PALF fiber shown in Figure 1, shows that demonstrates polygonal cross section, has no skin structure and very irregular in shape. The longitudinal view of surface represents that fibers are possessed with many obvious grooves. Consequently, PALF shows excellent cohesion in yarn.

\subsection{Tensile Properties of Fiber}

Tensile properties of PALF was summarized in Table 1 exerts that PALF has excellent tensile properties compared to most of the natural fibers. All these properties strongly evidence the spin ability of PALF to manufacture yarn.

\subsection{Tensile Properties of Yarn}

Table 2 illustrates that among the three yarns, PALF-Polyester blended yarn $(50 \%$ PALF $+50 \%$ Polyester) shows higher tensile properties than the others. This can be explained by the higher strength of polyester. Though PALF possessed 

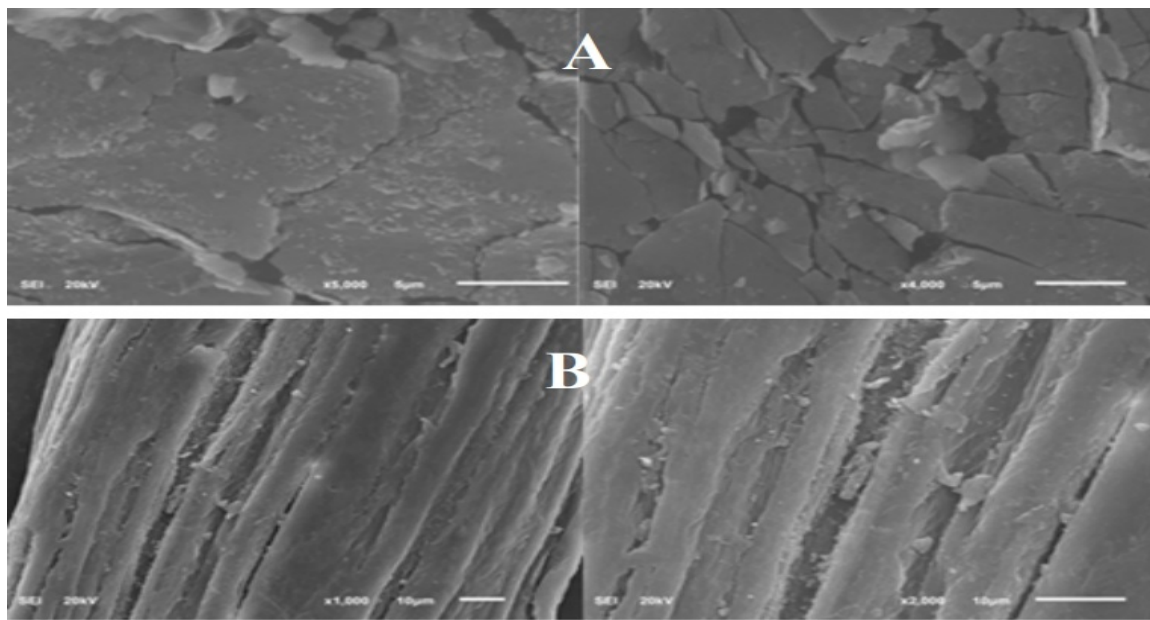

Figure 1. Cross sectional (a) and longitudinal (b) view of PALF.

Table 1. Tensile properties of pineapple leaf fiber.

\begin{tabular}{|c|c|c|c|c|c|c|c|c|c|}
\hline & $\begin{array}{l}\text { Breaking strength } \\
\text { centinewton }(\mathrm{cN})\end{array}$ & $\begin{array}{l}\text { Breaking } \\
\text { strength } \\
\text { 1/dTex }\end{array}$ & $\begin{array}{l}\text { Elongation at } \\
\text { break mm }\end{array}$ & $\begin{array}{l}\text { Elogation at } \\
\text { break } \%\end{array}$ & $\begin{array}{c}\text { Breaking } \\
\text { work } / \mathrm{cN}^{*} \\
\mathrm{~mm}\end{array}$ & $\begin{array}{l}\text { Breaking } \\
\text { time/s }\end{array}$ & $\begin{array}{c}\text { Yield } \\
\text { strength/cN }\end{array}$ & $\begin{array}{c}\text { Yield } \\
\text { elogation } / \mathrm{mm}\end{array}$ & $\begin{array}{c}\text { Initial } \\
\text { modulus } \\
\text { cN/dTex }\end{array}$ \\
\hline Average value & 44.01 & 4.40 & 0.77 & 3.85 & 15.774 & 2.31 & 10.813 & 0.264 & 76.714 \\
\hline $\begin{array}{l}\text { Maximum } \\
\text { value }\end{array}$ & 114.79 & 11.48 & 1.36 & 6.81 & 60.95 & 4.08 & 51.31 & 0.81 & 179.8 \\
\hline $\begin{array}{l}\text { Minimum } \\
\text { value }\end{array}$ & 11.42 & 1.14 & 0.38 & 1.88 & 2.33 & 1.13 & 1.12 & 0.01 & 17.32 \\
\hline $\mathrm{CV} \%$ & 47.37 & 47.37 & 30.67 & 30.67 & 70.93 & 30.64 & 100.805 & 69.68 & 51.54 \\
\hline
\end{tabular}

Table 2. Tensile properties of all types of yarn.

\begin{tabular}{cccccc}
\hline Yarn type & Yarn count $(\mathrm{Ne})$ & $\begin{array}{c}\text { Average breaking force } \\
(\mathrm{cN}) \text { centinewton }\end{array}$ & $\begin{array}{c}\text { Average elonga- } \\
\text { tion\% }\end{array}$ & $\begin{array}{c}\text { Average breaking } \\
\text { time/s }\end{array}$ & $\begin{array}{c}\text { Average tenacity } \\
(\mathrm{cN} / \text { Tex })\end{array}$ \\
\hline 100\% PALF & 10 & 479 & 5.78 & 2.23 & 9.39 \\
$50 \%$ cotton, 50\% PALF & 10 & 587 & 6.1 & 4.68 & 10.13 \\
$50 \%$ PALF, 50\%PE & 10 & 798 & 11.28 & 6.83 & 13.85 \\
\hline
\end{tabular}

excellent tensile properties, the yarn produced from the 100\% PALF shows lower mechanical properties compared two other two yarns. This is due to the less number of fibers, more specifically less surface area in the cross section of the yarn.

\subsection{Yarn Evenness}

Table 3 represents that in comparison to all three types of yarn, yarn produced from $100 \%$ PALF shows higher evenness. This can be explained by fiber fineness. The diameter of the PALF is higher than the cotton and polyester. Moreover, the fiber was processed with laboratory scale machinery and precision in mixing was not in expected level. Furthermore, PALF fibers were possessed 
Table 3. Evenness of different types of yarn.

\begin{tabular}{cccc}
\hline & $100 \%$ PLAF & 50 PLAF 50 Cotton & 50PLAF 50PE \\
\hline Uniformity U \% & 27.9 & 29.18 & 28.598 \\
CV m \% & 33.78 & 38.449 & 39.343 \\
Thin place-30\% & 10,890 & $15,255.9$ & $12,698.3$ \\
Thin place-50 \% & 4126 & 5701.9 & 4502.8 \\
Thick p 35 & 5998 & 6842.4 & 6312.3 \\
Thick 50 & 3453 & 5195.4 & 3952.9 \\
Neps +200\% & 5121 & 5758 & 5236.6 \\
\hline
\end{tabular}

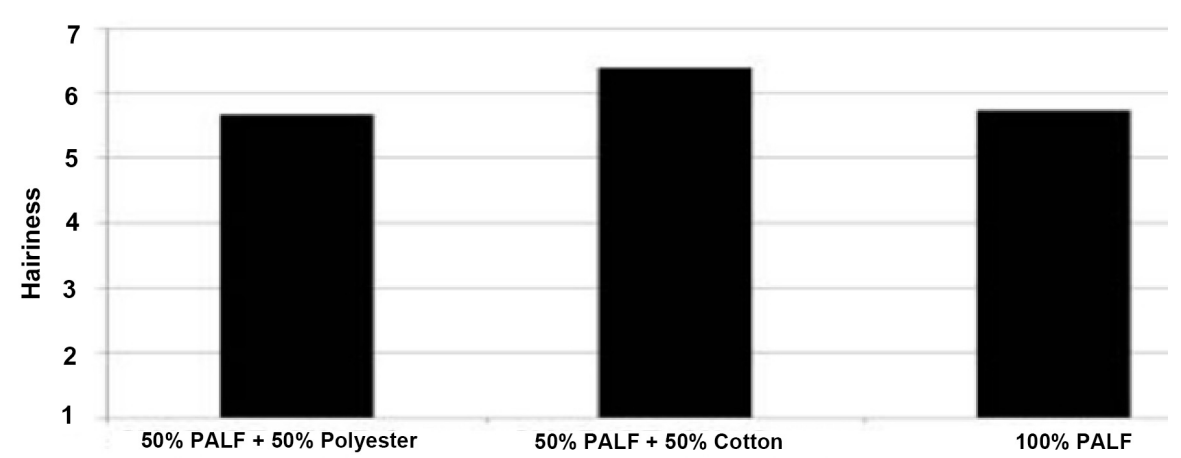

Figure 2. Hairiness of different types of yarn.

near about same characteristics thus produced more uniform yarn than the blended yarn.

\subsection{Yarn Hairiness}

Figure 2 shows that 100\% PALF contained yarn shows excellent properties in terms of hairiness. This is due to the presence of less amount of short fiber.

\section{Conclusion}

The method was found to utilize the pineapple leaf fiber as a cost-effective one because of its good performence in properties. All of three types of the yarn demonstrated good tensile properties in spite of poorness of yarn evenness when compared solo staple fibre yarn of same count. However accuracy in evenness could be achieved by effective pretreatment and through slight modification of spinning method. Due to being natural cellulosic fiber, pineapple leaf fiber (PALF) can be used on manufacturing apparels as a breathable and convienent version, because of having hydrophilic fiber. Via efficient modification PALF can be source of manufacturing garments.

\section{Conflicts of Interest}

The authors declare no conflicts of interest regarding the publication of this paper. 


\section{References}

[1] Sharma, U. (1981) Investigations on the Fibers of Pineapple [Ananas comosus (L). MERR.] Leaves. Carbohydrate Research, 97, 323-329. https://doi.org/10.1016/s0008-6215(00)80678-3

[2] Leao, A., Cherian, B.M., Narine, S., Souza, S.F. and Sain M. (2014) The Use of Pineapple Leaf Fibers (PALF) as Reinforcements in Composites. In: Farck, O. and Sain, M., Eds., Biofiber Reinforcements in Composites, Woodhead Publishing Ltd., 213. https://doi.org/10.1533/9781782421276.2.211

[3] Yusof, Y., Yahya, S.A. and Adam, A. (2014) A New Approach for Palf Productions and Spinning System: The Role of Surface Treatments. Journal of Advanced Agricultural Technologies, 1. https://doi.org/10.12720/joaat.1.2.161-164

[4] Dong, C.H., et al. (2014) Structure and Characteristics of Pineapple Leaf Fibers Obtained from Pineapple Leaves. Advanced Materials Research, 998-999, 316-319. https://doi.org/10.4028/www.scientific.net/amr.998-999.316

[5] Niles, S.N., Dias, W.P.P. and Perera, T.K.M. (2007) A Vision-Based Method for Analyzing Yarn Evenness. International Journal of Scientific \& Technology Research, 6, 254-256.

[6] Devi, L.U. and Bhagawn, S.S. (1997) Mechanical Properties of Pineapple Leaf Fiber-Reinforced Polyester Composites. Journal of Applied Polymer Science, 64, 1739-1748.

https://doi.org/10.1002/(sici)1097-4628(19970531)64:9<1739::aid-app10>3.0.co;2-t

[7] George, J., Bhagawan, S.S., Prabhakaran, N. and Thomas, S. (1995) Short Pineapples Leaf Fiber Reinforced Low Density Polyuthylene Composites. Journal of Applied Polymer Science, 57, 843-854. https://doi.org/10.1002/app.1995.070570708 